\title{
BUSCANDO INFORMAÇÕES CIENTÍFICAS NO INTERNET: SURGE O MAIS NOVO PRODUTO DA ANPET
}

\author{
Joaquim José Guilherme de Aragão \\ Mestrado em Transportes Urbanos \\ Universidade de Brasília
}

\section{INTRODUÇÃO}

Habemus SICT!

Hoje, a Internet passou a constituir um instrumento indispensável para a atualização e reciclagem dos profissionais de diversos setores. Pesquisar nessa super-rede faz parte das atividades de rotina daqueles que queiram buscar informações necessárias para o seu trabalho.

O Brasil, especialmente nossa comunidade técnica e científica na área de transportes, pode se orgulhar por dispor uma das mais completas listas de recursos WWW em transportes do mundo, sobretudo uma lista feita sob medida para as necessidades de técnicos e pesquisadores ${ }^{1}$.

O Sistema de Informação Científica em Transportes da Associação Nacional de Pesquisa e Ensino em Transportes visa constituir um útil

\footnotetext{
${ }^{1}$ Como o usuário irá reconhecer, ao estudar a página referente a outras listas de recursos, existem outros grandes sistemas cogêneres ao SICT/ ANPET, que, no entanto, estão mais voltados às necessidades de empresas ou simplesmente de amadores no assunto de transportes.
} 
instrumento de pesquisa para cientistas e técnicos da área de transportes de língua portuguesa (e também espanhola), acessando-lhes, de forma organizada, as páginas das principais instituições acadêmicas, técnicas, governamentais, internacionais e empresariais do mundo, ligadas direta ou indiretamente à questão dos transportes.

OSICT / ANPET está sendo construído pela equipe de docentes, alunos e estagiários do Mestrado em Transportes Urbanos da Universidade de Brasília, a qual, contudo, se encontra aberta para colaboração de qualquer interessado. A idéia é que, na medida em que a comunidade ANPET passe a utilizar esse serviço, ela também assuma, de forma cooperativa, seu desenvolvimento, que se encontra, a bem da verdade, ainda no início.

Alertamos, portanto, que o SICT / ANPET encontra-se ainda em fase de teste. Por outro lado, os endereços no WWW estão sendo permanentemente alterados, pelo que pedimos compreensão aos nossos colegas, caso alguma tentativa de contato não consiga o resultado esperado.

Inicialmente redigido em português, encontra-se em preparação uma versão em espanhol. Versões em inglês e francês pertencem aos planos para o futuro.

Por fim, assumimos, na confecção do presente sistema, que, dado o caráter eminente interdisciplinar desse campo científico, o especialista em transportes não é bitoladamente interessado apenas nas questões diretamente relacionadas com o transporte. Seu campo de interesse e análise transborda, portanto, em diversas questões das Engenharias e das Ciências Sociais, que designamos, aqui, de "áreas afins", e sobre as quais reunimos também informações, desde que de interesse imediato para o espacialista em transportes. 


\section{COMO ESTÁ CONSTRUÍDO O SICT/ANPET?}

OSICT / ANPET está estruturado nas seguintes sublistas:

Sistemas de Informação Científica - Esta sublista dá acesso a sistemas de informação científica (Ressources) semelhantes ao SICT/ANPET, ligados ou não ao setor de transportes, como também a restantes instrumentos de procura. Decompõe-se ela nas seguintes partes:

a) outras listas de recursos em transportes

b) outras listas de recursos em áreas afins

c) máquinas de procura

Instituições de Ensino e Pesquisa - Esta sublista, a mais completa de seu gênero em todo o WWW, acessa às páginas das principais instituições de ensino e pesquisa do mundo de interesse para o setor, subdividindo-se nas seguintes partes:
a) Brasil;
b) África;
c) Américas Central e do Sul;
d) América do Norte;
e) Ásia;
f) Austrália e Oceania;
g) Europa.

Associações e Demais Entidades Técnicas e Científicas - Listam-se, aqui, entidades associativas de natureza técnica e científica, de interesse direto ou indireto para o especialista em transportes. No momento, esta sublista subdivide-se da seguinte forma:
a) Brasil;
b) Estrangeiro.

Organismos Internacionais - Esta sublista decompõe-se em:
a) Organismos Internacionais vinculados ao setor de transportes;
b) Organismos Internacionais outros (porém de interesse para o nosso público)


Organismos Governamentais - Relaciona esta sublista organismos administrativos brasileiros e estrangeiros vinculados direta ou indiretamente à questão dos transportes. Seu desdobramento é o seguinte:
a) Brasil;
b) África;
c) Américas Central e do Sul;
d) América do Norte;
e) Ásia;
f) Austrália e Oceania;
g) Europa.

Organizações Sociais e Associações Empresariais - Listam-se, aqui, entidades associativas de natureza política e corporativa, tais como ONG's, sindicatos e associações empresariais, de interesse direto ou indireto para o especialista em transportes. No momento, esta sublista subdivide-se da seguinte forma:

a) Brasil;

b) Estrangeiro;

b1) Sindicatos e Associações de Empregados e Demais

Organismos Sociais não Empresariais;

b2) Associações e Entidades Empresariais no Transporte Urbano;

b3) Associações e Entidades Empresariais no Transporte

Rodoviário de Passageiros (não urbano e de turismo);

b4) Associações e Entidades Empresariais no Transporte Rodoviário de Carga;

b5) Associações e Entidades Empresariais no Transporte Ferroviário;

b6) Associações e Entidades Empresariais no Transporte Hidroviário;

b7) Associações e Entidades Empresariais no Transporte Aéreo;

b8) Associações e Entidades Empresariais no Transporte Intermodal e Agenciamento de Cargas;

b9) Outras Associações Empresariais no Setor de Transporte; b10) Associações e Entidades Empresariais na Construção de Infra-estruturas de Transporte; 
b11) Associações e Entidades Empresariais na Indústria de Equipamentos de Transporte;

b12) Associações e Entidades Empresariais na Consultoria; b13) Associações Empresariais em Outros Setores Conexos.

Empresas - Relaciona esta sublista empresas de transporte, de equipamentos, de construção e de consultoria. Atualmente, a página encontra-se em construção, listando apenas listas cogêneres sobre empresas vinculadas ao setor.

Bibliotecas - Esta sublista dá acesso às páginas de bibliotecas (em alguns endereços, até ao seu catálogo) do mundo inteiro ligadas à questão dos transportes e outras afins e a seus respectivos serviços abertos ao público externo. Desdobra-se ela nos seguintes segmentos:

a) Outras Listas de Bibliotecas

b) Bibliotecas Selecionadas

Bancos de Dados - Esta sublista desdobra-se em seguintes itens:

a) Bancos de Dados em Transportes;

b) Outros bancos de dados, porém de interesse para o estudioso dos transportes.

As páginas desses bancos indicam as condições de seu acesso, uma vez que, geralmente, estão abertos apenas a seus respectivos assinantes.

Bancos de Software - Como o nome indica, listam-se aqui os bancos de software em transporte.

Textos Eletrônicos - Acessa esta sublista a documentos eletrônicos livremente disponíveis no WWW, de interesse para o público do SICT/ ANPET. Para o futuro, planeja-se decompô-la em documentos gerais, revistas on-line, dados estatísticos, imagens, legislação e mapas. 
Revistas Especializadas em Transportes e áreas afins - Esta sublista acessa endereços de editores de revistas e de séries de publicações. Desdobra-se ela da seguinte forma:

a) Revistas Selecionadas sobre Transportes;

b) Revistas Selecionadas sobre áreas Afins;

c) Séries de Publicações sobre Transportes;

d) Séries de Publicações sobre áreas Afins;

e) Outras listas de publicações e revistas especializadas.

Serviços de Livraria - Acessa esta sublista páginas de principais editoras de relevante interesse para o público do SICT / ANPET e também de outros serviços gerais de encomenda e reenvio de publicações. Desdobrase ela da seguinte forma:

a) Editoras;

b) Serviços de venda de publicações de instituições;

c) Livrarias comerciais;

d)Outras listas de livrarias e editoras

Eventos Científicos em Transportes e áreas Afins - Acessa esta sublista dos principais eventos técnicos e científicos de interesse para o público do SICT / ANPET, desdobrando-se da seguinte forma:

a) Eventos selecionados;

b) Outras listas de eventos

Cursos - Acessa esta sublista a páginas de instituições e empresas que oferecem cursos de interesse para o público do SICT / ANPET.

Os cursos aqui relacionados têm natureza extra-curricular, na medida em que as informaçães pertinentes aos cursos da educação formal hão de ser obtidas ao se acessarem diretamente as instituições de ensino e pesquisa.

Listas de Discussão em Transportes e áreas afins - Acessa esta sublista listas de discussão de interesse para o público do SICT / ANPET.

Lista de Endereços Eletrônicos - Acessa esta sublista a listas de endereços eletrônicos de interesse para o público do SICT/ANPET. 
Páginas Pessoais - Acessa esta sublista a páginas pessoais de interesse para o público do SICT/ANPET.

Páginas Temáticas - Acessa esta sublista a páginas e listagens de páginas referentes a assuntos específicos do setor de transporte. Atualmente, estão disponíveis páginas sobre os seguintes temas:

a) Aspectos Ambientais e Energéticos dos Transportes;

b) Aspectos Jurídicos do Transporte;

c) Aspectos Sociais e Políticos do Transporte;

d) Ciclovias e Pedestres;

e) Economia e Gerência dos Transportes;

f) Engenharia de Tráfego e Segurança no Transporte;

g) Ensino e Pesquisa em Transportes;

h) História e Museus de Transporte;

i) Informatização e Automação em Transportes;

j) Modelos de Transporte e Sistemas de Informação Geográfica;

k) Novas Tecnologias de Transporte;

1) Planejamento dos Transportes;

m) Teletrabalho;

n) Transporte Aéreo;

o) Transporte Aquaviário;

p) Transporte de Carga e Logística;

q) Transporte e Desenvolvimento Urbano e Regional;

r) Transporte Dutoviário;

s) Transporte Ferroviário;

t Transporte Intermodal;

u) Transporte de Passageiros;

v) Transporte Rodoviário;

w) Outros Assuntos

\section{FUTUROS DESDOBRAMENTOS}

Apesar do tamanho já alcançado pelo SICT, o sistema encontra-se apenas no início de sua construção. Ele está sendo constantemente atualizado e enriquecido com novas informações, isso nas suas diversas páginas. Algumas melhorias de forma já se fazem sentir necessárias, 
tais como o aperfeiçoamento do lay-out e do processo de navegação interna, introduzindo-se também contador de acessos e uma máquina de procura. Futuramente será igualmente instalado um formulário automático (do tipo CGI-BIN), onde os usuários poderão sugerir o adicionamento de novos endereços.

Além disso, algumas páginas estão ainda subdesenvolvidas, como a página sobre as empresas e as páginas pessoais. Precisamos completar ainda a listagem de associações científicas e empresariais brasileiras, embora nem todas possuam um site.

Além desse aperfeiçoamento estrutural, vislumbram-se diversas opções de ampliação do nosso sistema de informações, com geração de seguintes novos produtos:

Fontes de recursos, nacionais e estrangeiros, para o financiamento de pesquisas;

Diretório Mundial da Pesquisa em Transportes, listando por assunto os diversos grupos e centros de pesquisa, inclusive as redes interinstitucionais, e os respectivos produtos;

Feira Internacional do Livro em Transportes, onde os livros produzidos por diversas editoras e instituições, do mundo inteiro, seriam listados por assunto, com possibilidade de acesso direto às páginas da editora / instituição e da obra listada. Esse serviço já encontra-se em desenvolvimento, e deve estar no ar até o final do ano; esperamos, com ele, facilitar às coordenações dos programas de graduação e pós-graduação em Transportes o árduo trabalho de levantar obras a adquirir;

Diretório Mundial de Legislação em Transportes.

Serão essas tarefas pioneiras em âmbito mundial, o que indica que sejam realizadas de forma cooperativa, com lastro em recursos próprios (de um projeto financiado). Haverão de participar não apenas instituições de ensino e pesquisa, mas também outros organismos sociais, governamentais e empresariais. 
Por fim, na medida em que o produto SICT/ANPET preserve seu pioneirismo e avanço a nível global, ele pode se transformar em um excelente instrumento de interação e divulgação da nossa comunidade nacional no âmbito internacional. Está igualmente prevista a edição de uma versão em espanhol e em inglês.

\section{O SICT/ANPET É NOSSO!}

Gostaríamos de finalizar reforçando o convite para que o desenvolvimento do sistema seja reconhecido como tarefa conjunta de toda a comunidade ANPET (estando também aberta à participação de outros atores externos). Além de sua ampla divulgação - tarefa essa que deve ser assumida pela Diretoria da Associação -, esperamos uma ativa participação das pessoas e instituições associadas na elaboração de diversos produtos e na sugestão de novos.

Em termos organizativos vai aí a sugestão que se construa um Comitê Gestor do SICT / ANPET, para que esse trabalho entre definitivamente na fase cooperativa. No dia que conseguirmos alcançar essa meta, teremos certamente um produto de peso na comunidade internacional, adquirindo a nossa comunidade nacional um grande renome mundial.

\section{Endereço (URL) do SICT/ANPET: http://www.unb.br/ft/enc/sict/}

